九州大学学術情報リポジトリ

Kyushu University Institutional Repository

Biological Control of Thrips palmi (Thysanoptera: Thripidae) with the Predatory Bug, Wollastoniella rotunda (Hemiptera: Anthocoridae) on Greenhouse Eggplant in Winter

Urano, Satoru

Institute of Biological Control, Faculty of Agriculture, Kyushu University

Shima, Katsuya

Institute of Biological Control, Faculty of Agriculture, Kyushu University

Hirose, Yoshimi

Institute of Biological Control, Faculty of Agriculture, Kyushu University

Nagai, Kazuya

Okayama Prefectural Agricultural Experiment Station

他

https://doi.org/10.5109/4502

出版情報：九州大学大学院農学研究院紀要. 47 (2)，pp. 325-331，2003-02-01. Faculty of Agriculture, Kyushu University

バージョン :

権利関係 : 


\title{
Biological Control of Thrips palmi (Thysanoptera: Thripidae) with the Predatory Bug, Wollastoniella rotunda (Hemiptera: Anthocoridae) on Greenhouse Eggplant in Winter
}

\author{
Satoru URANO ${ }^{1 *}$, Katsuya SHIMA ${ }^{1 * *}$, Yoshimi HIROSE ${ }^{1}$, Kazuya NAGAI' $^{2}$, \\ Kazuro OHNO ${ }^{3 * * *}$, Hiroyuki TAKEMOTO ${ }^{3}$ and Masami TAKAGI ${ }^{1 \dagger}$
}

\author{
'Institute of Biological Control, Faculty of Agriculture, Kyushu University, \\ Fukuoka 812-8581, Japan
}

(Received October 31, 2002 and accepted November 7, 2002)

\begin{abstract}
To evaluate the effectiveness of the predatory bug, Wollastoniella rotunda Yasunaga et Miyamoto, against Thrips palmi Karny on eggplants in greenhouses, we conducted experiments over two growing seasons. In the first experiment, 71 adults of $W$. rotunda were released in November 1997, and the release ratio was 1:4 (adult bug: thrips) for prey density of 0.06 thrips per leaf. This release was successful in controlling a T. palmi population that had such a low density at the release time. In the second experiment, a total of 180 nymphs of $W$. rotunda were released three times in October and November 1998. These releases were also effective in controlling a T. palmi population that had a low density ( 0.15 thrips per leaf) on the first release, and the release ratio of nymphal bugs to thrips was 1:2. Based on these results, we conclude that $W$. rotunda could be effective as a biological control agent against $T$. palmi in winter greenhouses.
\end{abstract}

\section{INTRODUCTION}

Thrips palmi Karny (Thysanoptera: Thripidae) is one of the most economic insect pests of eggplants both in greenhouses and in the field in Japan. Eggs and pupae of this thrips easily escape from insecticide applications, partly because of egg deposition in plant tissues and partly because of pupation in the soil (Kawai and Kitamura, 1990). Thus, repeated applications of insecticides are necessary to suppress the populations of T. palmi below economic injury levels and have resulted in the development of resistance by this pest to chemical insecticides (Takemoto and Ohno, 1996). Nagai (1993) proposed an integrated pest management (IPM) program for T. palmi on summer-autumn eggplant in the field. This program was based on the use of the predatory bug, Orius sauteri (Poppius) (Hemiptera: Anthocoridae) native to Japan and the selective chemicals harmless to this and other natural enemies of eggplant pests. Takemoto and Ohno (1996)

${ }^{2}$ Okayama Prefectural Agricultural Experiment Station, San'yo, Okayama 709-0801, Japan

${ }^{3}$ Fukuoka Agricultural Research Center, Chikushino, Fukuoka 818-8549, Japan

* Present address: Laboratory of Pest Management Systems, Kyushu National Agricultural Experiment Station, Nishigoshi, Kumamoto 861-1192, Japan

** Present address: Arysta Life Science Corporation, Tukuba, Ibaragi 305-0832, Japan

*** Present address: Laboratory of Applied Entomology, Faculty of Agriculture, Miyazaki University, Miyazaki 889-2192, Japan

† Corresponding author (E-mail: mtakagi@grt.kyushu-u.ac.jp) 
demonstrated the effectiveness of an IPM program in commercial eggplant fields. On greenhouse eggplants, Kawai (1995) experimentally showed that releasing Orius spp. from summer to autumn is successful in controlling T. palmi. However, he pointed out that population density of T. palmi increased as the densities of Orius spp. decreased after mid-October probably due to reproductive diapause of these predators under short-day (cf. Kingsley and Harrington, 1982; Nagai, 1993). . He also stated that in order to control T. palmi in winter, it may be necessary to lighten greenhouses or to use other non-diapausing predators.

In 1987 and 1988, Hirose et al. (1993) surveyed natural enemies of T. palmi in its native habitat Thailand, and recorded the predatory bug, Wollastoniella rotunda Yasunaga et Miyamoto (referred to as Billia sp., for details see Yasunaga and Miyamoto 1993) as an effective natural enemy of this pest. Because reproductive diapause of $W$. rotunda never occurred at $14 \mathrm{~L} 10 \mathrm{D}$ day length and $15^{\circ} \mathrm{C}$ (Shima, 1997), this predator could be a promising biological control agent against T. palmi on greenhouse eggplants in winter. However, there has been neither information on the effectiveness of $W$. rotunda in greenhouses in Japan nor attempts to its release for pest control in any country. In the present study, we released $W$. rotunda on greenhouse eggplants infested with $T$. palmi in winter to determine the effectiveness of this natural enemy.

\section{MATERIALS AND METHODS}

\section{Insects}

T. palmi were obtained from a colony established from adults and larvae that were collected in eggplant gardens in Hisayama, Fukuoka Prefecture, in 1995. The colony was maintained on potted kidney bean plants at $25^{\circ} \mathrm{C}$ and $16 \mathrm{~L} 8 \mathrm{D}$ in the laboratory.

W. rotunda were taken from a colony initiated from adults and nymphs that were collected in eggplant gardens in Bangkok, Thailand in 1995. Nymphs and adults of this predator were reared on Tyrophagus putrescentiae Schrank and Ephestia kuehniella Zeller (egg), respectively. Stems of young kidney beans were used as oviposition substrates for $W$. rotunda. The colony of this predator was kept in an incubator for more than one year at $25 \pm 1{ }^{\circ} \mathrm{C}, 75 \pm 5 \% \mathrm{RH}$, and $16 \mathrm{~L} 8 \mathrm{D}$.

\section{Experiments}

Experiments were conducted in Fukuoka Agricultural Research Center in Chikushino, Fukuoka, during winter two times, i. e. from 1997 to 1998 and from 1998 to 1999, using two plastic greenhouses $(9.1 \times 2.9 \mathrm{~m})$ for each experiment. Each greenhouse had openings on two sides, covered with mesh sleeves to avoid over heating and to prevent the insects from escaping. In each greenhouse, seedlings of 30 eggplants (cultivar "Chikuyo") were planted on Sept. 24, 1997 in two rows spaced $1.2 \mathrm{~m}$ apart and at intervals of $0.6 \mathrm{~m}$ between plants in a row. These plants were maintained till the end of the second experiment. The ground of each greenhouse was covered with black polyethylene films, a common practice for eggplant cultivation in Japan. Of the two greenhouses, one was used as a plot with $W$. rotunda release (hereafter BC plot) and the other as control plot. After the first experiment, all the shoots were trimmed in September 1998, and new offshoots that emerged from the stocks were used in the second experiment. 
In the first experiment, $60 \mathrm{~T}$. palmi adults were released in each plot on Oct. 20, 1997. Additional inoculation of 450 adults and 400 larvae of T. palmi in each plot was made on Oct. 30, 1997 by placing infested kidney bean on the plants. On Nov. 11, 71 adults of $W$. rotunda were released. The sex ratio of released $W$. rotunda adults was 0.5. In the release, $W$. rotunda adults were placed on four plants randomly chosen from BC plot together with $E$. kuehniella eggs which were previously killed by ultraviolet light.

In the second experiment, no T. palmi were released because the thrips were already established on Oct. 21,1998 . The $3 \mathrm{rd}$ instar nymphs of $W$. rotunda were released three times. These releases were conducted on Oct. 21, Oct. 28 and Nov. 4, 1998 using 60 nymphs for every time. On each release, methods for releasing the predator were the same as those in the first experiment.

\section{Sampling}

T. palmi populations were monitored every seven days from Nov. 4, 1997 to Jan. 5, 1998 in the first experiment, and from Oct. 21, 1998 to Jan. 4, 1999 in the second experiment. On each sampling date, numbers of $T$. palmi and $W$. rotunda were counted by naked eyes on four randomly selected plants per plot. We recognized four areas in a plant by height. A total of ten leaves was sampled per plant; four from the top area of the plant and every two from other three lower areas. Population densities of T. palmi were estimated by adjusting the number of insects on leaves from an area of a plant according to the number of branches belonging to the area. We recorded daily maximum and minimum temperatures in both plots during the experiments to calculate average monthly temperatures.

\section{RESULTS}

\section{The First Experiment}

Temperature fluctuations during the first experiment in BC plot are shown in Fig. 1a. Differences in monthly averages of maximum and minimum air temperatures between $\mathrm{BC}$ and control plots were less than $1^{\circ} \mathrm{C}$. Average monthly temperatures in both plots during the first experiment were $16.1,17.4$ and $18.0^{\circ} \mathrm{C}$ for November, December and January, respectively.

In control plot, T. palmi population increased exponentially except when temperatures were extremely low in December (Fig. 1b). In BC plot, $W$. rotunda were released at such a low T. palmi population density as 0.06 adults and larvae per leaf on Nov. 11 . The release ratio (ratio of the number of $W$. rotunda adults released to the number of $T$. palmi adults and larvae) was 1:4. Significant differences between the densities of two plots were detected on Nov. $25(P<0.01)$, Dec. $1(P<0.01)$, Dec. $8(P<0.01)$, Dec. 15 $(P<0.01)$, Dec. $29(P<0.01)$ and Jan. $5(P<0.0001)$ (Mann-Whitney $U$ test). On Jan. 5, T. palmi population density in $\mathrm{BC}$ plot was reduced to $1 / 7$ of that in control plot (Fig. 1b).

Two days after the release, we found 8, 8, 6 and 4 of $W$. rotunda alive on each 50 leaves of the four eggplants on which those were released. Six days after the release, we found $2,1,1$ and 0 of $W$. rotunda alive in the same way. This decrease of residents on 

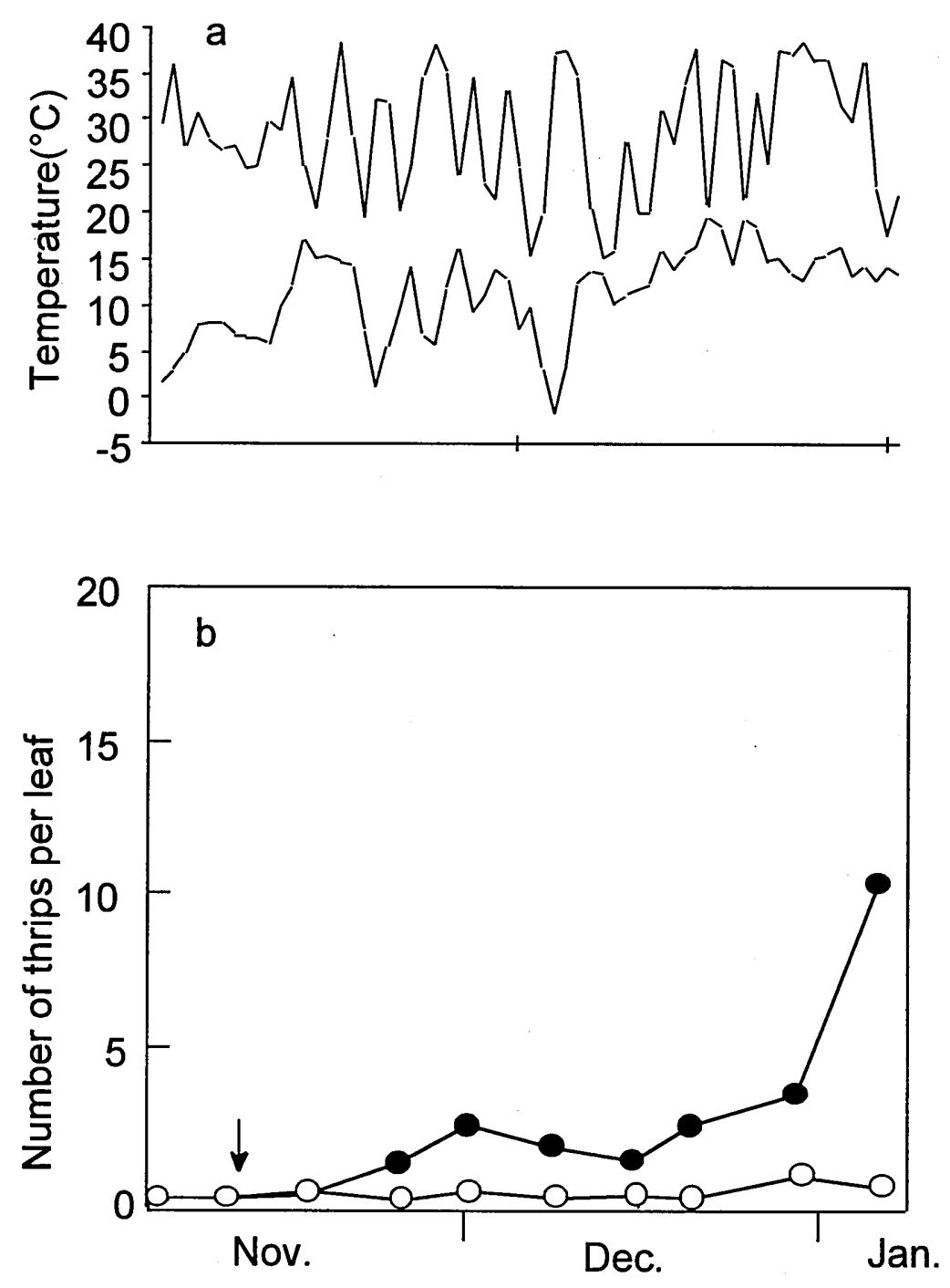

First experiment(4/11/1997-5/1/1998)

Fig. 1. Temperature and population fluctuations of T. palmi in the first experiment (1997-1998). a: Maximum (upper) and minimum (lower) daily air temperature in a plot with $W$. rotunda release. b: Density fluctuations of T. palmi adults and larvae in the control plot (black circle) and the release plot (open circle). Arrows indicate the release of $W$. rotunda. 
the released plants seemed to indicate that these predators rapidly dispersed. However, we were not successful in recording the population fluctuations of $W$. rotunda after its release because of extremely low densities of this predator.

\section{The Second Experiment}

Temperature fluctuations during the second experiment are shown in Fig. 2a.
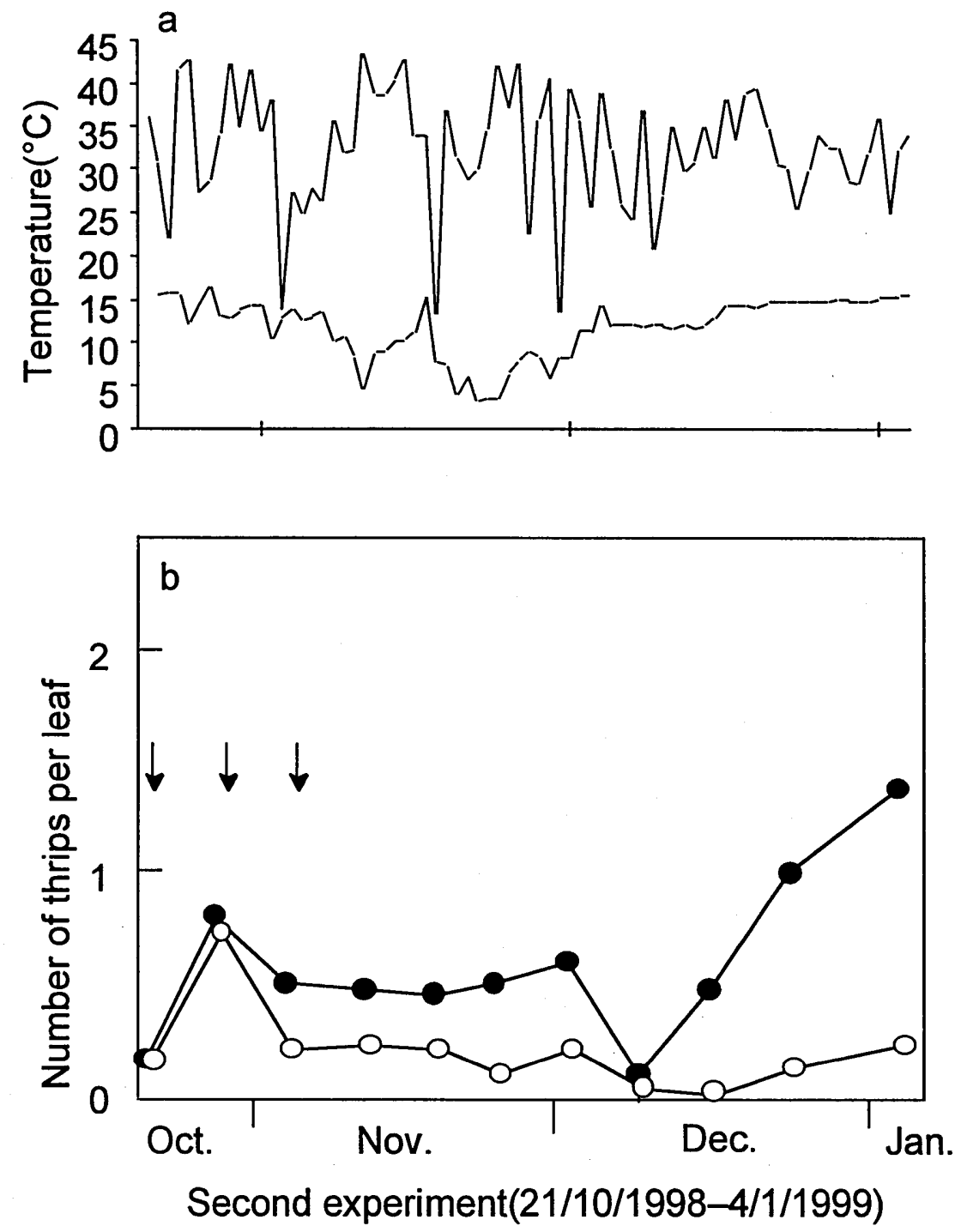

Fig. 2. Temperature records and population fluctuations of T. palmi in the second experiment (1998-1999). For further explanation, see Fig. 1. 
Average monthly temperatures were $20.7,16.1,17.4$ and $16.9^{\circ} \mathrm{C}$, in the latter half of October, November, December and January, respectively. In control plot, the T. palmi population fluctuated around 0.5 thrips per leaf for first 40 days, and after that it increased rapidly in the last three weeks. In BC plot, the releases were conducted for a low T. palmi population density, i.e. 0.15 adults and larvae per leaf, on the 1 st release on Oct. 21. The release ratio was 1:2. One day after the first release, we verified successful residence of released insects by finding $9,8,7$ and 7 of $3 \mathrm{rd}$ nymphs of $W$. rotunda alive on each 50 leaves of the four eggplants on which those were released. After three releases, T. palmi population density in BC plot flucturated around 0.2 thrips per leaf and showed no increase for a 60-day period. Significant differences between thrips population densities in both plots were detected on Nov. $25(P<0.05)$, Dec. $16(P<0.05)$, Dec. $24(P<0.01)$ and Jan. $4(P<0.01)$ (Mann-Whitney $U$ test). On Jan. 4, 1999, the thrips population density in $\mathrm{BC}$ plot was $1 / 6$ of that in control plot (Fig. 2b).

\section{DISCUSSION .}

It is important to determine if released predators are effective for a pest that has a low population density. They may disperse from a release plot at an extremely low prey population density. Kawai (1995) reported that when Orius spp. were released on each plant at a low population density of $T$. palmi ( 0.7 adults and larvae per leaf), the prey population was suppressed, fluctuating around 0.6 thrips per leaf for two months. In our experiments, $W$. rotunda were released at lower popuation densities of thrips $(0.06$ thrips per leaf in the first experiment and 0.15 thrips per leaf in the second experiment). Neverthless, these releases resulted in a slow increase in T. palmi population density to reach 1.5 thrips per leaf in the first experiment (Fig. 1b), and there was no increase in $T$. palmi population density in the second experiment (Fig. 2b). Both results indicate that $W$. rotunda releases are effective in controlling $T$. palmi populations that have such lower density at the release time.

Takemoto (unpublished) estimated an economic injury level (EIL) of T. palmi to be 17 adults and larvae per leaf as a permissible level of yield loss of $10 \%$ for eggplants in greenhouses from January to April. However, a good strategy for controlling T. palmi is not to keep this pest population density barely under EIL but to keep the population density low as long as possible. Our results demonstrated that $W$. rotunda is a promising biological control agent for such a purpose. Although $O$. sauteri also seems to have ability to control T. palmi populations having extremely low densities, it cannot act in winter season because of reproductive diapause under short-day.

Because $W$. rotunda takes 37.4 days in developing from egg to adult female at $20^{\circ} \mathrm{C}$ (Shima and Hirose, 2002), one could not expect a rapid increase of $W$. rotunda population after release in greenhouses. Release impacts of this natural enemy on T. palmi populations should depend on predation by released individuals in first few weeks after the release. Thus, for a release of $W$. rotunda, 3 rd instar nymphs would be more adequate than adults, because the cost of nymph production is lower than that of adult production and because predatory activity during nymphs and adults continues a longer period than that of adults alone. 


\section{ACKNOWLEDGEMENTS}

We thank Dr. J. Y. Honda for reading the manuscript. We also thank Ms. N. Nakamuta and for assistance in collecting the insects, and the staff of Fukuoka Agricultural Research Center for taking care of our experiments. Thanks are due to Dr. B. Napompeth and other staff of National Biological Control Research Center, Thailand, for their help in collecting $W$. rotunda in Thailand.

\section{REFERENCES}

Hirose,Y., H. Kajita, M. Takagi, S. Okajima, B. Napompeth and S. Buranapanichpan 1993 Natural enemies of Thrips palmi and their effectiveness in the native habitat, Thailand. Biol. Control, 3: 1-5

Kawai, A. 1995 Control of Thrips palmi Karny (Thysanoptera: Thripidae) by Orius spp. (Heteroptera: Anthocoridae) on greenhouse eggplant. Appl. Entomol. Zool, 30: 1-7

Kawai, A. and C. Kitamura 1990 Studies on population ecology of Thrips palmi Karny. 18. Evaluation of effectiveness of control methods of thrips on eggplant and sweet pepper using a simulation model. Appl. Entomol. Zool, 25: 161-175

Kingsley, P. C. and B. J. Harrington 1982 Factors influencing termination of reproductive diapause in Orius insidiosus (Hemiptera: Anthocoridae). Environ. Entomol, 11: 461-462

Nagai, K. 1993 Studies on integrated pest management of Thrips palmi Karny. Spec. Bull. Okayama Pref. Agric. Exp. Stn, 82: 1-55 (in Japanese with English summary)

Shima, K. 1997 An ecological study on the predator, Wollastoniella rotunda (Heteroptera: Anthocoridae), with special reference to its effectiveness as a possible control agent of Thrips palmi (Thysanoptera: Thripidae) in greenhouses in Japan during the winter. M. S. Thesis, Faculty of Agriculture, kyushu University, Japan. 47pp. (in Japanese with English summery)

Shima, K. and Y. Hirose 2002 Effect of temperature on development and survival of Wollastoniella rotunda (Heteroptera: Anthocoridae), a predator of Thrips palmi (Thysanoptera: Thripidae). Appl. Entomol. Zool, 37: 465-468

Takemoto, H. and K. Ohno 1996 Integrated pest management of Thrips palmi in eggplant fields, with conservation of natural enemies:' effects of surroundings and thrips communities on the colonization of Orius spp. In "Proceeding of International Workshop of Pest Management Strategies in Asian Monsoon Agroecosystems". Kyushu Experimental Station, Kumamoto, pp. 235-244

Yasunaga, T. and S. Miyamoto 1993 Three anthocorid species (Heteroptera: Anthocoridae), predators of Thrips palmi (Thysanoptera) in eggplant gardens of Thailand. Appl. Entomol. Zool, 28: 227-232 